\title{
Increasing the Impact of Canadian Research on Teaching and Learning in Post-Secondary Education
}

\author{
Ros Woodhouse \\ York University \\ Carole Dence \\ University of Ottawa
}

This paper builds on an inquiry process initiated during a session at the 2008 Society for Teaching and Learning in Higher Education conference. The goal was to promote scholarly research on teaching, learning, and educational development in Canadian post-secondary institutions by identifying and prioritizing research issues, and emerging collaborative strategies for inquiry into these issues. We reflect on the initial outcomes of the session and on strategies to increase the impact of research on teaching and learning in our institutions.

\section{Introduction}

$\longrightarrow$ arole and I are educational developers who share the goal of enhancing students' learning and academic experience by strengthening learning and teaching environments and practices; and a deep interest in how this agenda can be advanced across Canadian post-secondary institutions. Over time, we have seen a variety of initiatives and approaches emerge and recede both within Canada and internationally - for example, the 'assessment movement' (especially in the U.S.A.), 'Making Teaching Count' (in Canada), Teaching Quality Audits (in the UK, Australia, Ireland, and Hong Kong), credentialing of faculty development programs and faculty (in the UK), and more recently the Scholarship of Teaching and Learning (SoTL). This American-led movement seeks to improve teaching and learning by promoting faculty and instructor research into teaching and learning within their classrooms.

In the last few years, several Canadian universities and post-secondary institutions have invested in supporting the scholarship of teaching and learning as an educational development strategy. For example, Ryerson University, Kwantlen University College, and Queen's University are members of the Institu- 
tional Leadership program of the Carnegie Academy for the Scholarship of Teaching and Learning. Other Canadian institutions are assisting the scholarship of teaching and learning by other means, such as appointing educational researchers to support faculty in research on teaching and learning. However, not all post-secondary institutions have similar resources, and Canada lacks a national governmental agency or major foundation to enable such support across the post-secondary sector.

Given this context of limited resources, the question we address in this essay is: how can we increase the impact of research on teaching and learning in Canadian post-secondary institutions? Our answer is developed through reflection on the evolution and current state of the scholarship of teaching and learning, and on the research areas prioritized by participants in our conference session.

\section{The History of Faculty Research on Teaching and Learning}

Faculty research on teaching and learning has a long history, though it is difficult to trace because it was traditionally disseminated within disciplinary contexts rather than in common and identifiable locations. The literature is not only scattered across disciplines, but is distributed unevenly: research on teaching and learning has had a stronger presence in some disciplines than in others. For example, the literatures on management and medical education are extensive and reflect several decades of research, whereas the literature is more recent and limited to smaller fields which attract less funding and where the outcomes of education have lower stakes for the wider community.

The tradition of faculty research on teaching and learning has been given greater prominence since Hutchings and Shulman (1999) connected it to Boyer's (1990) proposal for a scholarship of teaching. Boyer proposed that universities had become too narrowly focused on research to the detriment of other academic roles and activities. He suggested defining these other activities - application of academic knowledge, integration of knowledge, and teaching
- as domains of scholarship to help them regain value within the academic community. Hutchings and Shulman built on this by reconnecting Boyer's scholarship of teaching with research, in this case research into learning and teaching. The connection was made in part to "advance the practice and profession of teaching and...bring to teaching the recognition afforded to other forms of scholarly work" (p. 10).

An additional role for faculty research on teaching and learning was emphasized by Patricia Cross. Cross and Steadman (1996) articulated the value of "classroom research" as a strategy by which faculty could increase their understanding of teaching and learning in their own disciplinary and institutional contexts and so become better teachers. Their association between classroom research and ongoing professional development is made clear by their description of the process as "continual and cascading" (p.12), and by their contrast between this programmatic, developmental approach and "one-shot" research studies intended to contribute to pedagogical understanding within the teaching and learning community.

Promotion of the scholarship of teaching and learning has continued and an international infrastructure has developed to support and advance it. Leadership for this movement has come from the Carnegie Foundation Centre for Advanced Study of Teaching and Learning (CASTL) and its programs. Other supporting organizations have been established, including an international society (the International Society for the Scholarship of Teaching and Learning [ISSOTL]), national and international conferences (international conferences include the London SOTL International Conferences, the ISSOTL Conferences, and the International Pedagogical Research Conference), and, more recently, new journals (for example, the International Journal for the Scholarship of Teaching and Learning, and the International Journal of Teaching and Learning in Higher Education). A considerable amount of faculty research on teaching and learning has been disseminated through these venues with a parallel literature on the meaning and assessment of the scholarship of teaching (written primarily by higher education researchers and educational developers). The discourse about this domain of scholarship continues to combine individual developmental 
goals with the political goals of improving the status of teaching as an academic activity. In this respect it is noteworthy that in a recent discussion of ten areas of impact for the scholarship of teaching, half reflected individual developmental goals, and the other half addressed the broader political goals of the movement (Ciccone, 2008).

Taken together, these developments indicate a significant level of research activity. However, the significance of this activity cannot be assessed using such a simple indicator. We explore the significance of 'typical' research output in the following section, and then draw out the implications for increasing the impact of research on teaching and learning on faculty, students, and post-secondary education in Canada.

\section{The Current State of Research on Teaching and Learning}

The focus on encouraging individual faculty to do research on their teaching has yielded a literature heavily weighted toward 'one-off' evaluation studies of how student learning is affected by an alteration of a teaching strategy within a single course. Faculty choices of interventions and evaluation measures are often motivated by individual interests, and the research findings are inextricably situated within the teaching and learning context where the research was carried out. It is also typical that such research is reported in a localized way, with few connections to similar studies conducted in other disciplinary settings or to how these studies relate to the broader educational literature. Despite the recent emergence of journals publishing research on teaching and learning, the literature remains scattered across the academic journal landscape.

We believe that it is difficult to apply or effectively incorporate much of this literature into one's own teaching. This is partly because it is difficult to infer important details of teaching practices and to learn new teaching skills from research reports. There is also uncertainty and so an element of risk about whether benefits reported in a 'one-off' study will generalize from the specific context where the research was conducted. It is harder still to build a clear overall picture of central research issues and progress from scattered sources and across poorly identified or connected issues. We contend that these difficulties severely limit the potential impact of faculty research on teaching and learning in our institutions.

\section{Proposals for Increasing the Impact of Research on Teaching and Learning in Canada}

We indicated earlier that some Canadian institutions are working to build capacity for high quality research on teaching and learning by leveraging institutional networks (for example, the CASTL networks of Institutional Leaders and Affiliates). In addition, these networks focus on themes, the majority of which are related to advancing the scholarship of teaching and learning. This approach may be effective for advancing the 'cause' of research/scholarship on teaching and learning, but it is not clear that this agenda is useful for advancing other teaching and learning issues relevant to post-secondary institutions in Canada. We will therefore focus our proposals on strategies which we believe will support advances across a range of issues.

\section{We propose that, as a first step, we need clarity and consensus on the primary goal(s) for promoting research on teaching and learning in Canada.}

One possible goal is based on Cross and Steadman's (1996) formulation of classroom research and the scholarship of teaching. This advocates research on teaching as a means to enhance individual faculty members' understanding of teaching and learning within a specific context. In other words, it is primarily a strategy for individual educational development, and only indirectly useful as a strategy to influence wider change (if, for example, participating faculty play an influential role in their institutions). Accordingly, we should limit our expectations for this model to achieve a direct and significant impact on teaching and learning within or beyond our institutions, un- 
less significant numbers of faculty become involved.

We note a potential irony in pursuing this approach to educational development. We have not been able to find research demonstrating the 'continual and cascading' process of ongoing research and teaching improvement suggested by Cross and Steadman (1996). Conversely, an empirical study of the relationship between research on teaching and teaching effectiveness suggests that highly effective teachers are more likely to conduct this kind of research than are faculty who are less effective teachers (Vajoczki et al., 2008). An implication of this study is that the benefits of improved teaching are limited to those who appear to need them least!

A different reason for promoting faculty research on teaching and learning is to bring about significant change in teaching and learning within and across our institutions. Here too we note a potential irony: evidence about teaching and learning is rarely a sufficient condition to impact attention much less action - in our institutions. Furthermore, when evidence-based recommendations conflict with preconceptions about teaching or about what can be accomplished within a given teaching context, they are as likely to be dismissed as acted on. For example, faculty who hold conceptions of teaching as the transmission of information may reject evidence that students benefit from interactive strategies in the classroom and argue that such strategies would not be viable in lecture settings. It is likely that changes in education - or any other aspect - of our institutions are more likely to be triggered and sustained by strong internal forces (such as changes in leadership or the need to maintain program accreditation), or external forces (such as the economy and government priorities and policies) than by research evidence.

The limitations of current faculty research on teaching and learning, together with the complexities of organizational change, suggest that simply increasing the intensity or amount of faculty research on teaching and learning is an inadequate strategy for accomplishing significant change in our institutions. However, explicitly encouraging the "continual and cascading" approach recommended by Cross and
Steadman (1996) may be worthwhile as an individualized and ongoing, high-level professional development strategy for those faculty who are already effective teachers.

\section{We propose a strategic, focused, and collaborative approach to research on teaching and learning.}

As we argued earlier, integrating and interpreting a scattered and fractured body of research is a challenging task for those involved in the research and even more so for others who might benefit from it. One way to address the challenge of integrating existing research, and so potentially to increase its impact, would be to encourage review papers that bring together research from all sources by focusing on given topics. Examples of this approach within medical education are the conceptual reviews solicited by the Society of Directors of Research in Medical Education, and the Best Evidence in Medical Education (BEME) series which build on the tradition of systematic reviews developed within the Cochrane and Campbell Collaborations on biomedical and social/educational research, respectively. Coordinating such reviews within, and especially across, disciplines requires an infrastructure to establish review criteria, identify topics, organize groups of reviewers, train them in methodology, and identify a predictable outlet for publication to help others locate these reviews. Establishing such an infrastructure would be a useful step and would help us make more effective use of existing research.

A second strategy for increasing the impact of Canadian research on teaching and learning is to encourage research which extends beyond evaluations of interventions by individuals. In other words, we need to foster research on deeper and wider educational issues relevant to individual faculty and other stakeholders in post-secondary education. We can produce and organize research more effectively by encouraging a focused, collaborative, and strategic research agenda. We also believe that strategic decisions about the research agenda must be made by faculty rather than by agencies or specialist researchers who are removed

\footnotetext{
${ }^{1}$ We thank an anonymous reviewer for this suggestion.
} 
from daily teaching activities and contexts.

Our first step toward a 'proof of concept' for a faculty-driven strategic research agenda was to invite colleagues attending the 2008 Society for Teaching and Learning in Higher Education Conference to collaborate in identifying a set of priority issues for future research on educational development. A small but enthusiastic group of educational developers, an educational researcher, and an interested faculty member participated in a modified nominal group technique, a method devised for planning by achieving a consensus on priorities (Delbecq \& Van de Ven, 1971). The procedure was conducted in four phases. We introduced the goals of the session and the process we would be using. Then, participants independently generated salient issues and questions for future research, recording each one on a separate sticky note. As notes were completed, they were gathered and distributed in an unordered manner across a large flat surface. When the generation phase was complete, participants worked collaboratively to cluster the ideas into themes, which were then discussed and labeled by the group and then annotated by a session facilitator.

A detailed account of the results is beyond the scope of this essay. Based on our experience with this method for developing an educational research agenda in other settings, the group was as productive as many larger groups have been. Beyond a simple list of topics, the group identified overarching contextual issues (such as the evolving roles of higher education), and questions reflecting many perspectives on the actual and potential role, practices, and impact of educational development. In our view, the session was highly successful as both proof of concept as an approach for developing a collaborative agenda, and as a pilot for more extensive inquiry into a research agenda for Canadian educational developers.

\section{We propose that those involved in doing or using research on teaching and learning must advocate for research support.}

It is difficult to accomplish high quality, useful research by simply adding it to routine educational responsibilities. As with research in other areas, it is critical to provide time, materials, and access to a community with shared research interests. As mentioned earlier, research on university-level teaching and learning - other than teacher education - rarely receives support from Canada's major granting agencies. A few Canadian universities offer grants and/ or release time for research. However, the scale of such institutional support is necessarily limited. In particular, we have not been able to find models offering sustained support over time, despite the value of extended time periods for replicating investigations to mitigate some of the design limitations of 'classroom-based research,' and for building a stable research community.

The 'faculty learning community' model which is widely-used (and often well-resourced) in the US could help to improve these conditions. However, faculty learning communities are typically supported with resources which have been provided 'up front' to facilitate the community and its activities. In effect, the advocacy for resources has already been accomplished. Unfortunately, participation and potential benefits are restricted to those in institutions who can afford this model or access external funding (such as Federal Improvement of Post Secondary Education grants), which is not available in Canada.

\section{Conclusions}

Whether the goal of research on teaching and learning in post-secondary institutions is to improve the recognition of teaching as an academic activity, inform the professional development of individual faculty, or have widespread impact on teaching and learning practices, it is imperative to increase its quality and integration. We can make small advances individually and within our institutions. However, if research on teaching and learning in post-secondary institutions is to have significant impact, we need to be honest about the limitations of what has been accomplished to date, to establish consensus on our research priorities and a vision of what can be accomplished, and to advocate for the resources to realize this vision. If we cannot advocate for ourselves, it is unlikely that anyone else will do it on our behalf. 


\section{References}

Boyer, E.L. (1990). Scholarship reconsidered: The priorities of the professoriate. Jossey Bass Publishers: San Francisco.

Ciccone, T. (2008, January). Examining the impact of SOTL. The International Commons, 12-13.

Cross, K.P. \& Steadman, M. H. (1996). Classroom research: Implementing the scholarship of teaching. San Francisco: Jossey-Bass Publishers.

Delbecq, A.L. \& Van de Ven, A. (1971). A group process model for problem identification and program planning. Journal of Applied Behavioral Sciences, 7, 467-492.

Hutchings, P. \& Shulman, L.S. (1999). The scholarship of teaching: New elaborations, new developments. Change, 31, 10-15.

Vajoczki, S., Borin, P., Kustra, E., Martin, L., Sana, F., \& Savage, P. (2008). Scholarly teaching and scholarship of teaching and learning: Is there a connection? Presentation at the annual conference of the Society for Teaching and Learning in Higher Education, University of Windsor, Windsor, Ontario.

\section{Biographies}

Ros Woodhouse is the Academic Director at the Centre for the Support of Teaching at York University, Toronto, Ontario. Her research interests focus on learning and teaching in Higher Education, with a special focus on knowledge mobilization.

Carole Dence is an Educational Development Consultant and presently, an Interim Director of the Centre for University Teaching at the University of Ottawa, Ontario. She is an active member of STLHE and the Educational Developers Caucus. 